\title{
DISCUSSION
}

\section{Micromechanics of creep of granular materials}

\author{
G. R. McDOWELL (2003). Géotechnique 53, No. 10, 915-916
}

T.-W. Feng, Chung Yuan Christian University, Taiwan According to equation (3) and equation (6), the following equation can be derived:

$$
\log \left(\frac{\sigma_{\mathrm{c}}}{\sigma_{\mathrm{c} 0}}\right)=\frac{1}{n} \log \left(\frac{t_{0}}{t}\right)
$$

Equation (10) can be used to plot the relationship between the time of creep, $t$, and the applied stress, $\sigma_{\mathrm{c}}$, with $n$ values of 10 and 100, as shown in Fig. 1. It can be seen from Fig. 1 that the applied stress is decreasing with time, and this seems to be in contradiction to the fact that creep is developed under constant effective stress. The author proposed that the mechanics of both primary compression and creep lie in the fracture of the smallest grains and cited Leung et al. (1996) for evidence of sand particles crushing during creep of one-dimensional compression. However, it can be seen from Leung et al. (1996) that it was the angular corners of large grains that were crushed during creep. It is highly plausible that a continuous crushing of corners of sand particles is accompanied by a continuous rearrangement of sand particles.

Equation (1) can be rewritten as

$$
\Delta e=C\left(1+e_{0}\right) \log \left(\frac{t}{t_{0}}\right)
$$

Therefore $C\left(1+e_{0}\right)$ is equal to the secondary compression index $C_{\alpha}$. Thus

$$
C=\frac{C_{\mathrm{c}}}{1+e_{0}} \frac{C_{\alpha}}{C_{\mathrm{c}}}
$$

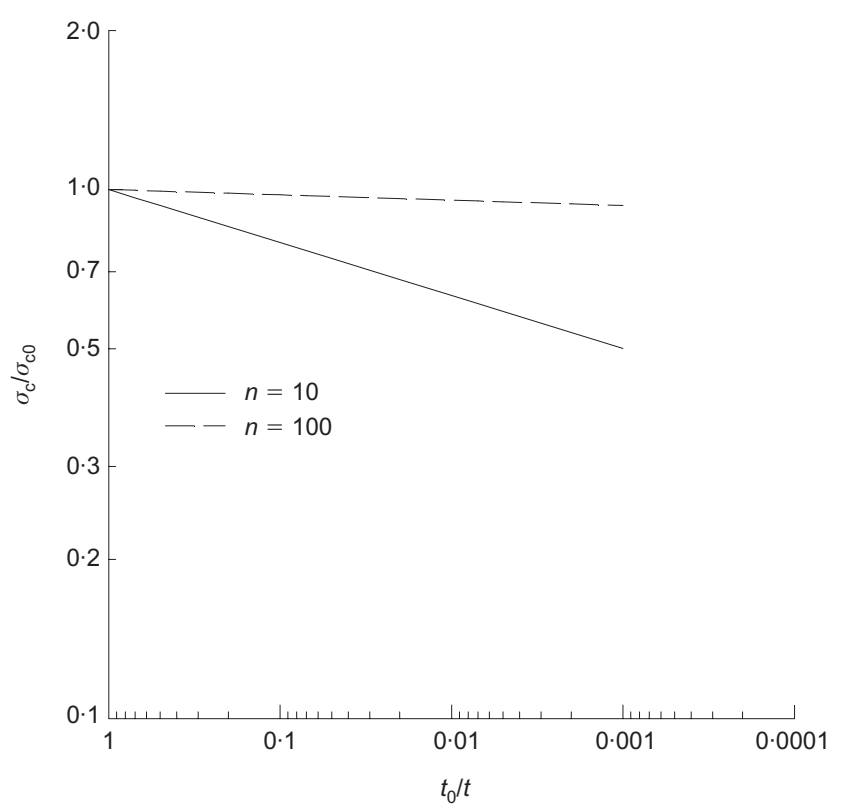

Fig. 1. Predicted relationship between applied stress and time of creep
It can be shown from equation (2) that $\lambda=C_{\mathrm{c}} / 2 \cdot 3$, where $C_{\mathrm{c}}$ is the compression index. Mesri et al. (1990) found that values of $C_{\alpha} / C_{\mathrm{c}}$ for a variety of sands range from 0.01 to $0 \cdot 02$. Thus, taking an initial void ratio $e_{0}=0 \cdot 5, \lambda=0 \cdot 1$, and $C_{\alpha} / C_{\mathrm{c}}=0.015$, the value of creep coefficient $C$ is computed to be 0.0023 , which is within the typical range as described by the author. It may be noted that the concept of a constant $C_{\alpha} / C_{\mathrm{c}}$ value for any soil has been well established, and the mechanism of secondary compression or creep has been proposed as a continuing process of particle rearrangements (Terzaghi et al., 1996). Equation (12) implies that the mechanisms of particle rearrangements during creep with or without particle crushing are the same.

Furthermore, a relationship between the slow crack growth exponent $n$ and the compressibility ratio $C_{\alpha} / C_{\mathrm{c}}$ can be derived. It can be shown from the definition of $C_{\mathrm{c}}$ and $C_{\alpha}$ that

$$
\log \left(\frac{\sigma_{\mathrm{c}}}{\sigma_{\mathrm{c} 0}}\right)=\frac{C_{\alpha}}{C_{\mathrm{c}}} \log \left(\frac{t_{0}}{t}\right)
$$

Comparing equation (10) and equation (13), one obtains

$$
\frac{C_{\alpha}}{C_{\mathrm{c}}}=\frac{1}{n}
$$

By using equation (14), a value of $C_{\alpha} / C_{\mathrm{c}}=0.015$ gives a value of $n=67$, which may be representative for carbides and nitrides. For organic clays the typical value of $C_{\alpha} / C_{\mathrm{c}}$ is about 0.05 (Terzaghi et al., 1996), which leads to a value of $n=20$, which may be representative for oxides. These together imply that $n$ may be a constant for any material, just as $C_{\alpha} / C_{\mathrm{c}}$ has been found to be a constant for any soil.

Many measured curves of one-dimensional compression void ratio against logarithm of stress for granular soils are highly non-linear, so that the compression index $C_{\mathrm{c}}$ varies with the stress. This means that $\lambda$ is not a constant, as $C_{\mathrm{c}}=$ $2 \cdot 3 \lambda$. For example, the curves of one-dimensional compression void ratio against logarithm of stress from Golightly (1990) for dense carbonate sand, loose silica sand and dense silica sand are used to compute the value of compression index at different stresses, and the results are shown in Fig. 2. It can be seen from Fig. 2 that the compression index $C_{\mathrm{c}}$ first increases with stress and then decreases with stress. The variation of creep coefficient $C$ with stress may be computed by using equation (12), the $C_{\mathrm{c}}$ data in Fig. 2, and a representative $C_{\alpha} / C_{\mathrm{c}}$ value of 0.015 ; the results are shown in Fig. 3. It is clear from Fig. 3 that the value of $C$ first increases with stress and then decreases with further increase in stress.

\section{Author's reply}

I am grateful to the discusser for his contribution. However, his interpretation of equations (3) and (6) appears to be incorrect. He has taken the stress $\sigma_{\mathrm{c}}$ to be the applied stress. However, the stress $\sigma_{\mathrm{c}}$ is a yield stress. Plastic compression occurs when the applied stress exceeds this value, or when the yield stress (which is proportional to the strength of the smallest grains) reduces as time increases at constant applied 


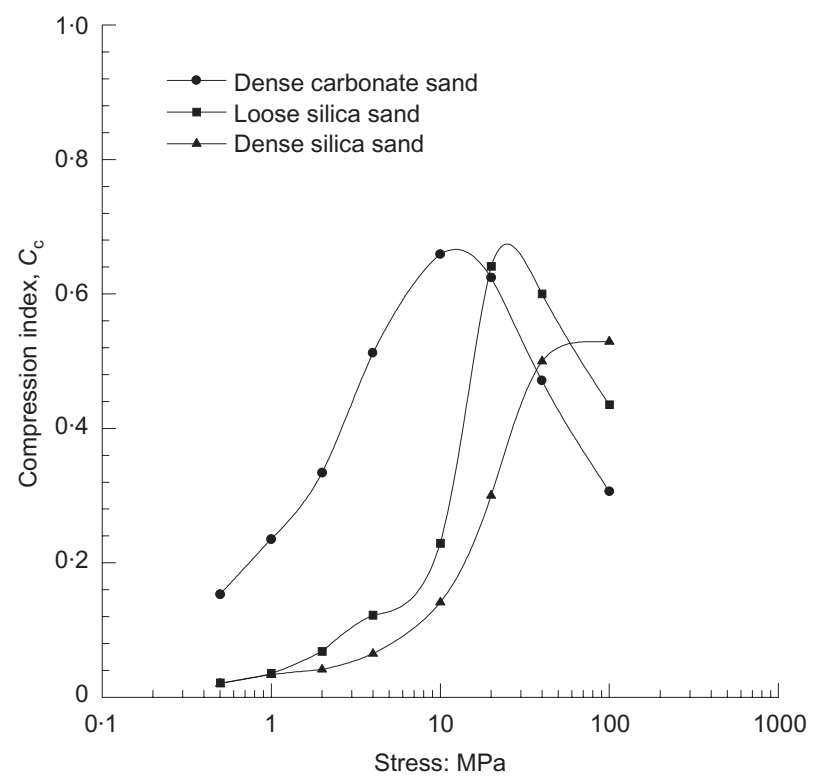

Fig. 2. Variations of compression index with stress

stress. The discusser's equation (10) therefore simply shows the reduction of yield stress with time. In other words, for a soil that is being one-dimensionally normally compressed, for decreasing strain rates, the normal compression line in $e-\log \sigma$ space moves to the left. The rest of the discusser's analysis is based largely on his incorrect assumption that $\sigma_{\mathrm{c}}$ is the applied stress, but he arrives at equation (14) in the end. This is exactly the same as my equation (9), and I am very grateful to him for pointing out that my analysis is consistent with experimental data which suggests that $C_{\alpha} / C_{\mathrm{c}}$ should be a constant for a given soil (Terzaghi et al., 1996) and that typical values of $C_{\alpha} / C_{\mathrm{c}}$ found in the literature (Mesri et al., 1990; Terzaghi et al., 1996) are correctly predicted by equation (9) for typical values of $n$. This lends much credibility to the proposition that creep is caused by the fracture of the smallest particles owing to the time dependence on strength.

The discusser points out that creep is caused by particle rearrangement, which is true. What I have tried to do is propose a mechanism that is consistent with observed data.

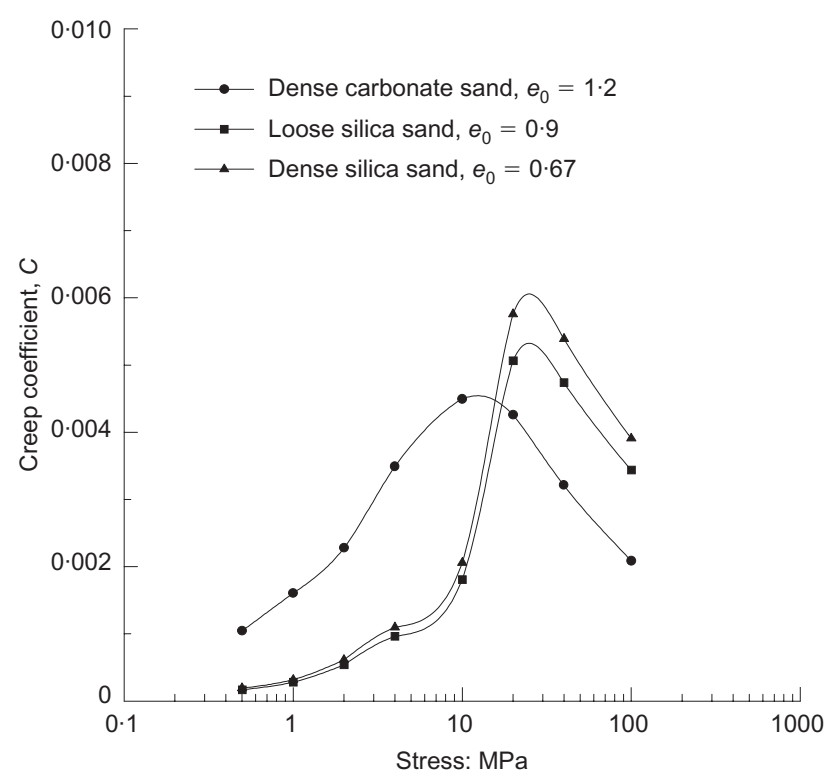

Fig. 3. Variations of creep coefficient with stress

That mechanism is the filling of small voids by small particles. These small particles could be formed by the bulk fracture of slightly larger particles, or by the fracture of small asperities. Both will result in the trigger of particle rearrangement as small voids become filled. The suggestion by the discusser that $C_{\alpha} / C_{\mathrm{c}}$ should be a soil property supports the argument that both primary and secondary compression originate from the crushing of the smallest grains and subsequent particle rearrangement.

\section{REFERENCES}

Golightly, C. R. (1990). Engineering properties of carbonate sands. $\mathrm{PhD}$ thesis, Bradford University.

Leung, C. F., Lee, F. H. \& Yet, N. S. (1996). The role of particle breakage in pile creep in sand. Can. Geotech. J. 33, 888-898.

Mesri, G., Feng, T. W. \& Benak, J. M. (1990). Postdensification penetration resistance of clean sands. J. Geotech. Engng ASCE 116, No. 7, 1095-1115.

Terzaghi, K., Peck, R. B. \& Mesri, G. (1996). Soil mechanics in engineering practices, 3rd edn. New York: Wiley. 